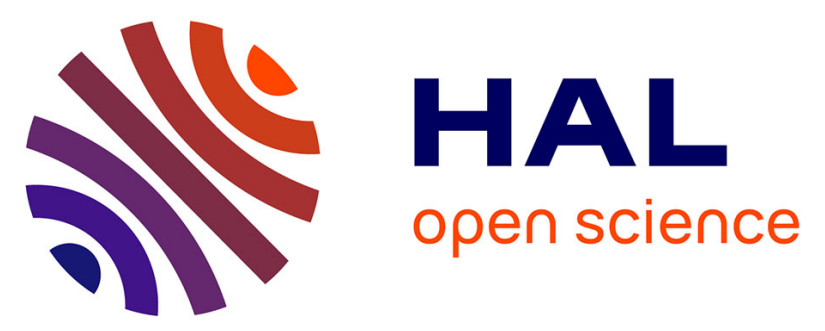

\title{
Highly axial magnetic anisotropy in a N3O5 dysprosium(III) coordination environment generated by a merocyanine ligand
}

\author{
Pramila Selvanathan, Gang Huang, Thierry Guizouarn, Thierry Roisnel, \\ Guglielmo Fernandez-Garcia, Federico Totti, Boris Le Guennic, Guillaume \\ Calvez, Kévin Bernot, Lucie Norel, et al.
}

\section{To cite this version:}

Pramila Selvanathan, Gang Huang, Thierry Guizouarn, Thierry Roisnel, Guglielmo Fernandez-Garcia, et al.. Highly axial magnetic anisotropy in a N3O5 dysprosium(III) coordination environment generated by a merocyanine ligand. Chemistry - A European Journal, 2016, 22 (43), pp.15222-15226. 10.1002/chem.201603439 . hal-01360879

\section{HAL Id: hal-01360879 https://hal.science/hal-01360879}

Submitted on 2 Feb 2017

HAL is a multi-disciplinary open access archive for the deposit and dissemination of scientific research documents, whether they are published or not. The documents may come from teaching and research institutions in France or abroad, or from public or private research centers.
L'archive ouverte pluridisciplinaire HAL, est destinée au dépôt et à la diffusion de documents scientifiques de niveau recherche, publiés ou non, émanant des établissements d'enseignement et de recherche français ou étrangers, des laboratoires publics ou privés. 


\title{
Highly axial magnetic anisotropy in a $\mathrm{N}_{3} \mathrm{O}_{5}$ dysprosium(III) coordination environment generated by a merocyanine ligand
}

\author{
Pramila Selvanathan, ${ }^{[a]}$ Gang Huang, ${ }^{[b]}$ Thierry Guizouarn, ${ }^{[a]}$ Thierry Roisnel, ${ }^{[a]}$ Guglielmo Fernandez- \\ Garcia, ${ }^{[a, c]}$ Federico Totti, ${ }^{[c]}$ Boris Le Guennic, ${ }^{[a]}$ Guillaume Calvez,${ }^{[b]}$ Kévin Bernot, ${ }^{*[b]}$ Lucie Norel ${ }^{*[a]}$ \\ and Stéphane Rigaut ${ }^{[\mathrm{a}]}$
}

\begin{abstract}
A spiropyran-based switchable ligand isomerizes upon reaction with lanthanide(III) precursors to generate complexes with unusual $\mathrm{N}_{3} \mathrm{O}_{5}$ coordination sphere. The air stable dysprosium(III) complex shows a hysteresis loop at $2 \mathrm{~K}$ and a very strong axial magnetic anisotropy generated by the merocyanine phenolate donor
\end{abstract}

Single molecules as active elements have been considered as potential building blocks for future nanoelectronic systems because of their advantages in cost, scalability, component density, and power consumption. ${ }^{[1]}$ To achieve an efficient molecular-based switching operator, a key physical property should be modulated by one or more external stimuli, such as light or electricity. ${ }^{[2]}$ For instance, conductivity, ${ }^{[3]}$ optical ${ }^{[2]}$ or magnetic ${ }^{[4]}$ properties can be modulated with the help of those stimuli leading to a reversible transformation between two forms displaying different properties. Single Molecule Magnets (SMM), which at low temperature behave as tiny magnets at the molecular scale, have attracted enormous interest in recent years, ${ }^{[5]}$ and the switching of their magnetic caracteristics is also raising more and more attention. If few examples of redox modulation have been reported so far, ${ }^{[6]}$ a total, robust, and reversible photo-switching process remains to be achieved with 4f-based SMM. ${ }^{[7]}$

On the other hand, photo-induced change of the coordination environment of lanthanide ions has been demonstrated upon the photoisomerization of spiropyran or spirooxazine ligands. ${ }^{[8]}$ Such isomerization induces large changes in the relaxivity ${ }^{[9]}$ or the luminescence $^{[10]}$ of the complexes. Consequently, lanthanide complexes based on spiropyran ligands ${ }^{[11]}$ are ideal candidates for the photo-control of slow relaxation of magnetization since spiropyran (SP) to merocyanine (MC) isomerization is expected to lead to drastic modifications in the lanthanide ion environment and in fine, in the related magnetic properties (Scheme 1).

With this initial aim, we demonstrate herein that the SP moiety is a useful precursor for the synthesis of unique lanthanide

[a] P. Selvanathan,T. Guizouarn,T. Roisnel, G. Fernandez-Garcia, B. Le Guennic, L. Norel, S. Rigaut

Institut des Sciences Chimiques de Rennes, UMR 6226 CNRS Université de Rennes 1

263 Avenue du Général Leclerc, 35042 Rennes Cedex (France)

E-mail: lucie.norel@univ-rennes1.fr

[b] G. Huang, G. Calvez, K. Bernot

INSA, Institut des Sciences Chimiques de Rennes UMR 6226

F-35708 RENNES.

E-mail : kevin.bernot@insa-rennes.fr.

[c] G. Fernandez-Garcia, F. Totti

Department of Chemistry "Ugo Schiff" and INSTM RU, University of Florence

50019 Sesto Fiorentino (Italy) complexes that display SMM properties. Indeed, this strategy afforded non-photochromic $\mathrm{Y}, \mathrm{Yb}$ and Dy complexes that bear a merocyanine ligand and display an unprecedented $\mathrm{N}_{3} \mathrm{O}_{5}$ environment. On the basis of ab initio calculations, a very strong axial magnetic anisotropy of the dysprosium center can be predicted for such environment and explained by the presence of a highly charged phenolate oxygen that belongs to the merocyanine ligand. We therefore rationalize why this $\mathrm{N}_{3} \mathrm{O}_{5}$ environment lead to a great SMM behavior with a hysteresis loop at $2 \mathrm{~K}$ and an energy barrier of $216 \mathrm{~K}$.

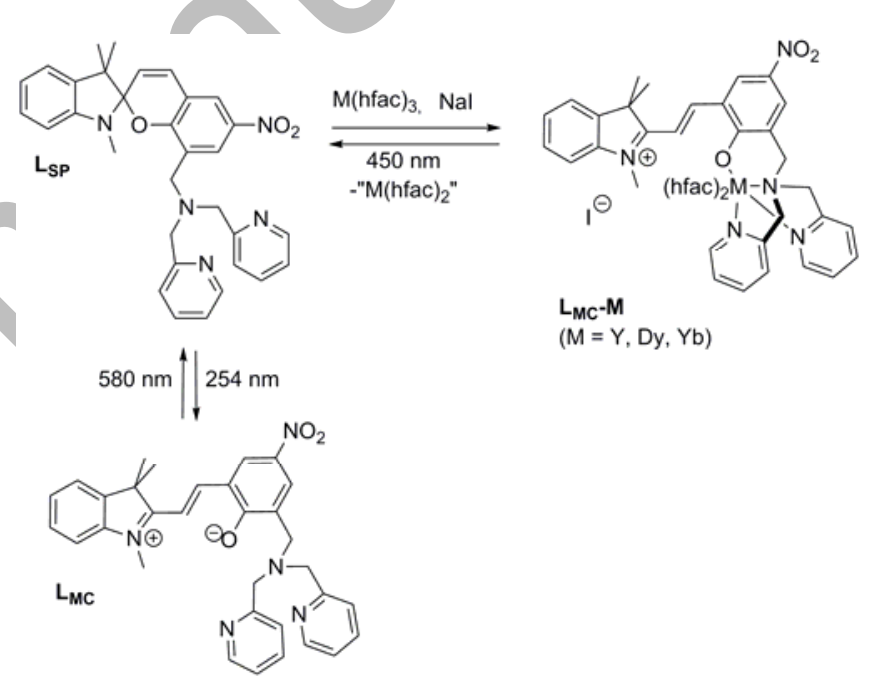

Scheme 1. Synthesis of $L_{M C}-M$ complexes from the spiropyran ( $\left.L_{S P}\right)$ ligand and isomerization towards the merocyanine $\left(L_{M C}\right)$ form.

In order to provide a strong coordination towards $\operatorname{Ln}(\mathrm{III})$ ions, the chelating SP ligand LSP has been synthesized from 8(iodomethyl)spirobenzopyran ${ }^{[12]}$ and bis(2-pyridinemethyl)amine and fully characterized (see $\mathrm{SI}$ ). Reaction of $\mathrm{L}_{\mathrm{SP}}$ with one equivalent of $\mathrm{M}(\mathrm{hfac})_{3} \cdot 2 \mathrm{H}_{2} \mathrm{O} \quad\left(\mathrm{M}=\mathrm{Dy}, \mathrm{Yb}, \mathrm{Y} ; \mathrm{hfac}^{-}=\right.$ hexafluoroacetylacetonate) in the presence of sodium iodide give rise to a coordination-induced isomerization of $L_{S P}$ into $L_{M C}$, the merocyanine analogue (Scheme 1). The monometallic complex $\mathbf{L}_{\mathbf{M C}}-\mathbf{M}$ that is formed is obtained as single crystals (in $17 \%$ yield for $L_{M C}-D y, 40 \%$ for $L_{M C}-Y$ and $42 \%$ for $\left.L_{M C}-Y b\right)$ and its composition is established as $\left[\mathrm{M}(\mathrm{hfac})_{2}\left(\mathrm{~L}_{\mathrm{MC}}\right)\right]$ l where the iodide anion provides neutrality to the crystal packing. The Dy analogue ( $\left.L_{M C}-D y\right)$ crystallizes in the monoclinic $P 21 / c$ space group. The $M C$ form is clearly identified (Figure 1). $L_{M C}$ acts as a tetradentate ligand towards the dysprosium center since the three nitrogen atoms of the bis(2-pyridinemethyl)amine moiety and the phenolate oxygen atoms are involved in coordination 
bonds. To accommodate the tetradentate MC ligand, one hfac ligand has been released by the Dy ${ }^{\prime \prime \prime}$ center, a process which is not unprecedented. ${ }^{[13]}$ Four oxygen atoms from the two hfac ligands complete the coordination sphere and the Dy ${ }^{\text {III }}$ ion is thus octa-coordinated. The Dy-O bonds lengths are between 2.31 and $2.38 \AA$ for the oxygen of the hfac ligands and 2.219(3) $\AA$ for the phenolate oxygen whereas $\mathrm{Dy}-\mathrm{N}$ bonds are longer than 2.50 $\AA$. The resulting coordination geometry is close to a triangular dodecahedron $\left(\mathrm{D}_{2} \mathrm{~d}\right)$ as shown by SHAPE analysis (see $\left.\mathrm{SI}\right) .{ }^{[14]}$ The shortest intermolecular Dy-Dy distance is $9.50 \AA$. Y $\mathrm{Yb}^{\mathrm{III}}$ and $Y^{\prime \prime \prime}$ derivatives are found isostructural (Table S1) with the Dy ${ }^{\prime \prime \prime}$ one, even if full crystal structure solving has not been possible on the latter. It is worth to note that the standard thermal equilibrium between MC and SP isomers is totally shifted toward the MC form by the formation of the phenolate-lanthanide bond. This phenomenon has been described in solution for a variety of spiropyran derivatives with various $3 \mathrm{~d}^{[15]}$ or $4 \mathrm{f}$ metal ions. ${ }^{[11,16]}$ However, this is the first time that a MC-lanthanide complex is structurally characterized.
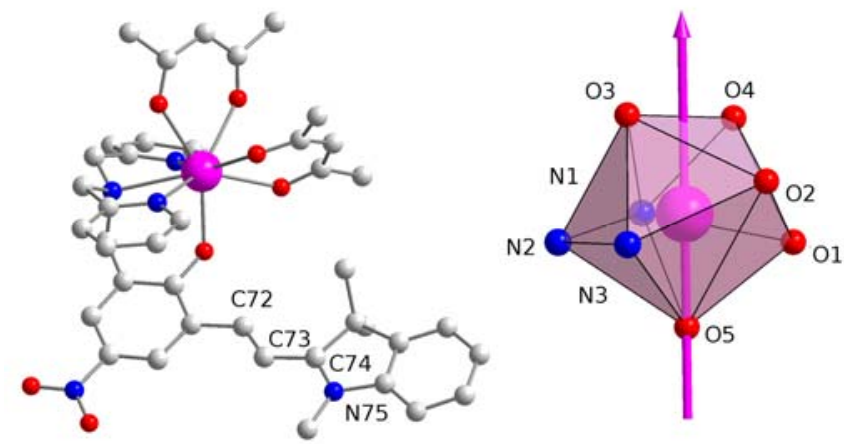

Figure 1. Left. Schematic representation of $L_{M C}-D y$ (fluorine, hydrogen and iodine atom omitted for clarity). Right: Coordination polyhedron with calculated magnetic anisotropy axis. Bond lengths $(\AA)$ are $\mathrm{Dy}-\mathrm{O} 5=2.219(3)$, Dy $-\mathrm{O} 1=$ 2.386(3), Dy - O2 = 2.315(3), Dy - O3 = 2.336(3), Dy - O4 = 2.384(3), Dy $\mathrm{N} 1=2.516(3), \mathrm{Dy}-\mathrm{N} 2=2.550(3), \mathrm{Dy}-\mathrm{N} 3=2.523(3)$. For $\mathrm{Yb}$, the bond lengths $(\AA)$ are $\mathrm{Yb}-\mathrm{O} 5=2.186(3), \mathrm{Yb}-\mathrm{O} 1=2.337(4), \mathrm{Yb}-\mathrm{O} 2=2.263(4)$, $\mathrm{Yb}-\mathrm{O} 3=2.294(4), \mathrm{Yb}-\mathrm{O} 4=2.347(4), \mathrm{Yb}-\mathrm{N} 1=2.467(4), \mathrm{Yb}-\mathrm{N} 2=$ $2.507(4), \mathrm{Yb}-\mathrm{N} 3=2.482(4)$.

Further studies in solution by NMR, absorption and emission spectroscopies could demonstrate the robustness of the $\mathbf{L}_{M C}-\mathbf{M}$ complexes upon dissolution and the completeness of the coordination-induced isomerization process. In $\mathrm{CD}_{3} \mathrm{CN}$, the ${ }^{1} \mathrm{H}$ NMR spectrum of diamagnetic $L_{M C}-Y$ shows a single set of resonances (Figure S3). The MC isomer is clearly evidenced with the two double bond protons signals at 8.37 and $7.18 \mathrm{ppm}$ with $\mathrm{J}=16.0 \mathrm{~Hz}$, typical of trans coupling. Moreover, coordination of the bis(2-pyridinemethyl)amine part is proven by the broadening of the pyridine rings signals at $8.54,7.84$ and $7.35 \mathrm{ppm}$ and from the changes of the signals of the $\mathrm{N}^{-\mathrm{CH}_{2}-}$ pyridine group : observed as a sharp singlet at $2.70 \mathrm{ppm}$ in free SP (Figure S1), this signal experiences a large shift and a splitting as a set of strongly coupled doublets integrating $4 \mathrm{H}$ (for two equivalent $A B$ systems) upon coordination to $Y^{\prime \prime \prime}$. The absorption spectra of $L_{M C}-M$ complexes (the behavior of $L_{M C}-Y$ is shown on Figure 2 as an example) notably show an absorption in the visible range, centered at $468 \mathrm{~nm}\left(\varepsilon=21500 \mathrm{~mol}^{-1}\right.$.L.cm $\left.{ }^{-1}\right)$, assigned to a MC centered charge transfer transition that is markedly blue shifted as compared to free $L_{M c}\left(\lambda_{\max }=554 \mathrm{~nm}\right)$ because of the decreased donor ability of the phenolate once coordinated. Upon excitation in this band $(\lambda=450 \mathrm{~nm})$, all $\mathbf{L}_{M C}-\mathbf{M}$ $(\mathrm{M}=\mathrm{Y}, \mathrm{Yb}, \mathrm{Dy})$ compounds show the same broad emission band centered at $570 \mathrm{~nm}$, typical of merocyanine chromophores $^{[17]}$ (Figures S4-S6). This red emission is usually enhanced and blue shifted in metal complexes of merocyanine involving the phenolate in comparison with free merocyanines. ${ }^{[18]}$

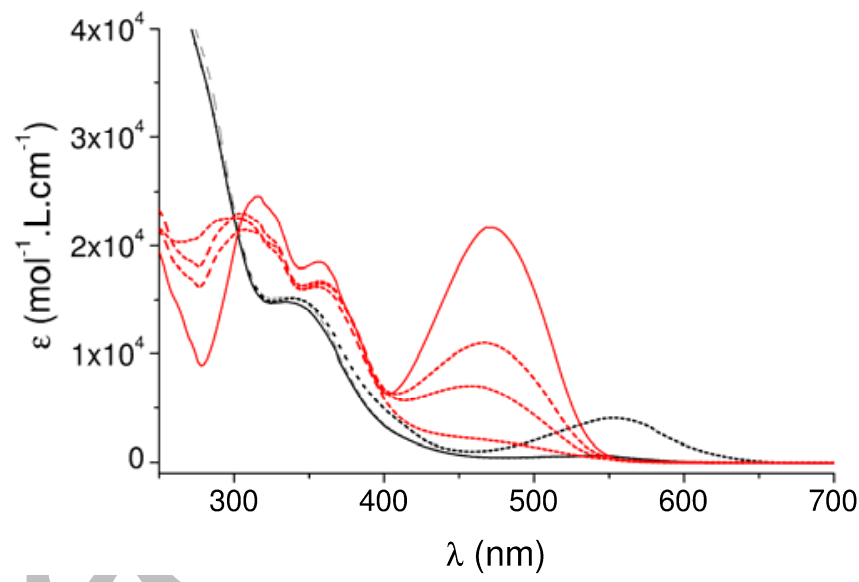

Figure 2. Electronic absorption spectra in acetonitrile of $L_{M c}-Y$ (red line) and upon $450 \mathrm{~nm}$ irradiation during $3 \mathrm{~h}, 6 \mathrm{~h}$ and $15 \mathrm{~h}$.(red dots) Electronic absorption spectra in acetonitrile of $L_{\text {sp }}$ before (black line) and after (black dots) $254 \mathrm{~nm}$ irradiation during $10 \mathrm{~min}$, followed by $580 \mathrm{~nm}$ irradiation for $10 \mathrm{~min}$ (grey dots). irradiat

Under visible light irradiation, the spectroscopic properties of $\mathrm{L}_{\text {MC }}-\mathbf{M}$ complexes showed a drastic evolution. First, irradiation at $450 \mathrm{~nm}$ leads to an almost total and irreversible bleaching of the visible transition (Figure 2). This bleaching can be followed as well by the decrease of the detected emission at $570 \mathrm{~nm}$ when successively measuring several emission spectra with $450 \mathrm{~nm}$ excitation wavelength (Figure S4). During this process, the ${ }^{1} \mathrm{H}$ NMR spectrum shows a decrease of $L_{M C}-Y$ signals in favor of the ones of free $L_{s p}$ (Figure S3). It means that the photoisomerization to the spiropyran form induces a decoordination of the $\mathrm{Y}(\mathrm{hfac})_{2}$ moiety. Indeed, a new singlet at $6.16 \mathrm{ppm}$ is observed, in the range of yttrium diketonate protons and could correspond to a free $\left[\mathrm{Y}(\mathrm{hfac})_{2} \mathrm{~L}_{4}\right]\left(\mathrm{L}=\mathrm{CD}_{3} \mathrm{CN}\right)$ complex. The photo-release of the metal is clearly irreversible either by UV irradiation or thermally.

The observed behavior is reminiscent of $\mathrm{M}^{\mathrm{n}+}$ cations sensors based on spiropyran ligands in which the metal complexation induces isomerization to the $\mathrm{MC}$ form whereas the release of the metal ion is induced upon visible light irradiation. ${ }^{[10,19]}$ In our case, the photo-induced state is of limited interest as far as magnetic switching is concerned. However the peculiar coordination sphere observed for $\mathbf{L}_{M C}-\mathbf{M}$ complexes prompted us to evaluate their magnetic behavior. With this aim, the synthesis, crystallization and sampling of all complexes have then been undertaken in the dark. 
The magnetic behaviors of $\mathrm{L}_{M C}-\mathrm{Dy}$ and $\mathrm{L}_{\mathrm{MC}}-\mathrm{Yb}$ have been investigated by static (dc) and dynamic (ac) measurements in the solid state. For $L_{M C}-D y$ the room temperature value of $X_{M} T$ (Figure S7) was found lower than the predicted value (14.17 emu $\mathrm{K} \mathrm{mol}^{-1}$ ) for one Dy ${ }^{\mathrm{III}}$ ion $\left({ }^{6} \mathrm{H}_{15 / 2}, \mathrm{~S}=5 / 2, \mathrm{~L}=5\right.$, and $\mathrm{g}=4 / 3$ ) and that the $a b$ initio calculated value $\left(13.89 \mathrm{emu} \mathrm{K} \mathrm{mol}{ }^{-1}\right.$, see SI) The dynamic magnetic measurements clearly evidence a clean and significant slow relaxation of magnetization for $L_{M C}$-Dy under zero static field $\left(\mathrm{H}_{\mathrm{dc}}=0\right)$. It becomes temperature independent below $5 \mathrm{~K}$ (Figure S8) and the relaxation time $(\tau)$ saturates around $100 \mathrm{~Hz}\left(\tau_{(2 \mathrm{~K})}=1.5810^{-3} \mathrm{~s}\right)$. This relaxation can be enhanced for an optimal $H_{d c}=1200$ Oe (Figure 3) as commonly observed on Dy-based SMMs. ${ }^{[20]}$

The analysis of the magnetic relaxation in the high temperature region highlights a thermally activated behavior that can be assumed to follow an Arrhenius law $\left(\tau_{0}=\tau_{0} \exp (\Delta / \mathrm{k} T)\right.$ where $\tau_{0}$ is the characteristic relaxation time and $\Delta$ the energy barrier for spin reversal. $\mathrm{L}_{\mathrm{MC}}$-Dy presents a particularly high value of $\Delta=$ $216 \mathrm{~K}\left(150 \mathrm{~cm}^{-1}\right)$ with $\tau_{0}=4.710^{-9} \mathrm{~s}$ (Table S2, Figure 4a). For $\mathrm{H}_{\mathrm{dc}}=1200 \mathrm{Oe}$, very weak saturation of the relaxation time is observed at low temperature. This is associated with a significantly narrow distribution of the relaxation times as demonstrated by the analysis of the normalized Argand plots. Indeed, $\alpha_{\max }$ (expected to be zero for a single relaxation time and 1 for a spin-glass-like behavior) is equal to 0.177 at its maximum $(7.5 \mathrm{~K})$ (Table S5 and Figure $4 \mathrm{~b})$. One can note that for $H_{d c}=0$ Oe, $\alpha$ values are even smaller (Table S3, Figure S9).
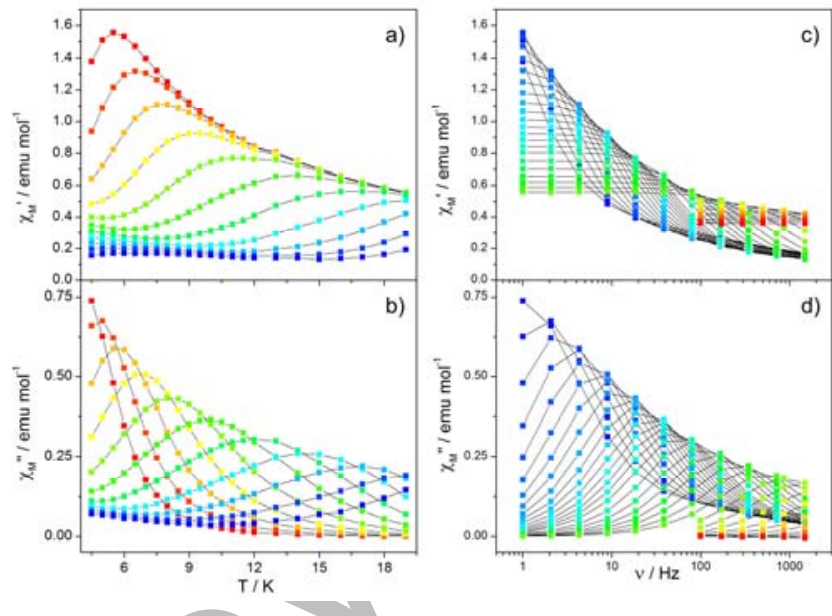

Figure 3. Dynamic magnetic measurements of $L_{M c}-D y$ with $H_{d c}=1200$ Oe Frequency dependence (color mapping from 1 to $1500 \mathrm{~Hz}$ ) of the a) in-phase $\left(X_{M}^{\prime}\right)$ and b) out-of-phase ( $\left.X_{M}^{\prime \prime}\right)$ magnetic susceptibilities. Temperature dependence (color mapping from 4 to $19 \mathrm{~K}$ ) of the $\mathrm{c}$ ) in-phase d) out-of-phase magnetic susceptibilities.
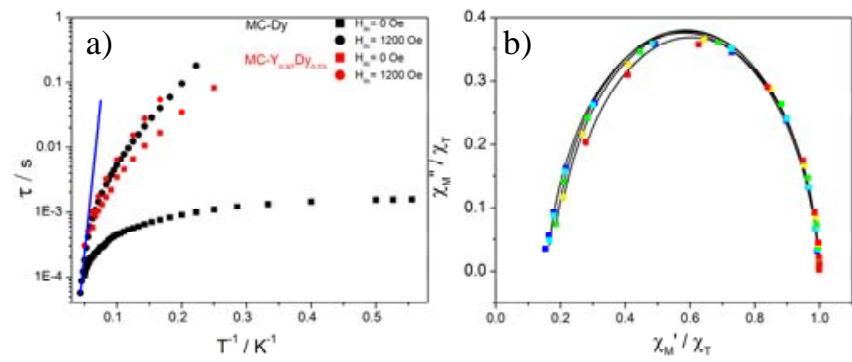

Figure 4. a) Temperature dependence of the relaxation times for $L_{M C}-D y$ and $L_{M C}-Y_{0.97} D y_{0.03}$. b) Argand plot for the $H_{d c}=1200$ Oe measurement of $L_{M c}$-Dy at selected temperatures between $10 \mathrm{~K}$ (blue) and $18 \mathrm{~K}$ (red).

The original coordination environment observed in $\mathbf{L}_{M C}-\mathrm{Dy}$ therefore lead to a remarkable slow relaxation behavior and $A b$ initio calculations (CASSCF/SI-SO) have then been performed to rationalize this behavior. The calculations confirm the high magnetic anisotropy of $\mathrm{L}_{\mathrm{MC}}$-Dy. The wavefunction of the ground state consists in remarkably pure $\mid M_{j}>= \pm 15 / 2$ well separated $\left(211 \mathrm{~cm}^{-1}\right)$ from the first excited state (mainly $\left.\mid M_{j}>= \pm 13 / 2\right)$ in agreement with the large $\Delta$ value observed. Additionally, the ground state $g$ tensor is found highly anisotropic $\left(g_{x}=0.00, g_{y}=\right.$ $0.01, g_{z}=19.80$ ) (Table S12) and the magnetic anisotropy axis is almost perfectly collinear to the Dy- $\mathrm{O}_{\text {phenolate }}$ bond (Figure 1). It is worth notice that the consideration of the iodide anion in the calculations does not modify all these findings. The orientation of the anisotropy axis is in agreement with the electrostatic surroundings around the Dy ${ }^{111}$ ion ${ }^{[21]}$ with the $\mathrm{O}_{\text {phenolate }}$ atom being from far the most negatively charged atom of the coordination sphere. Such influence of the phenolate donor, has been recently illustrated by the highly axial crystal field and record magnetization reversal barrier obtained within pentagonal bipyramid dysprosium(III) complexes having two phenolate donor in a trans disposition. ${ }^{[22]}$ In $\mathrm{L}_{\mathrm{MC}}$-Dy this is even reinforced by the organization of the three poorly charged nitrogen atoms that form a plan that is almost perpendicular to Dy- $\mathrm{O}_{\text {phenolate }}$ bond (Table S13).

The mononuclear nature of $\mathbf{L}_{\mathbf{M C}}$-Dy allows for its dispersion in a diamagnetic matrix in order to further optimize its SMM behavior. ${ }^{[23]}$ Isomorphous solid-solution with yttrium has been synthesized with an expected doping rate of $5 \%$ that has been corrected to $3.3 \%$ on the basis of the magnetic measurements. The doped compound, $\mathrm{L}_{M C}-\mathrm{Y}_{0.97} \mathrm{Dy}_{0.03}$, shows as expected, an enhanced magnetic slow relaxation (Figures S10-S13, Tables S6-S9). In particular, relaxations with $\mathrm{H}_{\mathrm{dc}}=0$ Oe and $\mathrm{H}_{\mathrm{dc}}=1200$ Oe became similar because the saturation of $\tau$ in zero field is removed (Figure 4a). This is clear evidence that the temperature independent magnetic relaxation in $L_{M C}-D y$ is induced by intermolecular interactions. The range of temperatures where magnetic slow relaxation is observed is shifted toward high temperatures and distribution of the relaxation times is lowered $\left(\alpha_{\max }=0.095\right)$ (Figure S10, Table S9).

As a result of the high magnetic anisotropy of $L_{M C}-D y$, both pure and yttrium-doped samples show significant opening of magnetic hysteresis loops below $2 \mathrm{~K}$ (Figures S14 and S15) and at $0.5 \mathrm{~K}$, clear opening is visible in the \pm 5000 Oe region (Figure 5). 


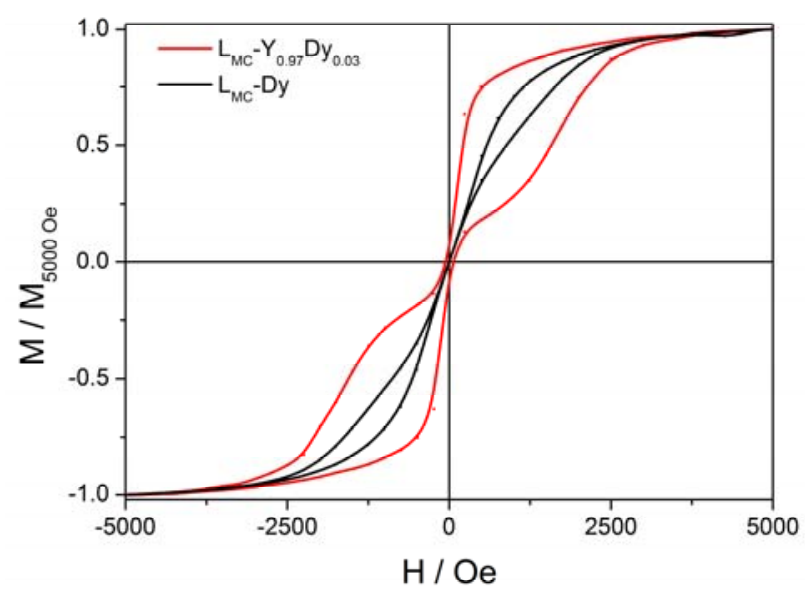

Figure 5. Magnetic hysteresis loops measured at $0.5 \mathrm{~K}$ with a magnetic field sweep rate of 15.5 Oe. $\mathrm{s}^{-1}$. Curves are normalized by the magnetization value at 5000 Oe for easy comparison.

Similar investigations of the magnetic properties have been performed on $\mathrm{L}_{\mathrm{MC}} \mathrm{-} \mathbf{Y b}$ (Figures S16-S17, Tables S10-S11). However the dynamic magnetic behavior is significantly less spectacular $\left(\Delta=6.8 \mathrm{~K}, \tau_{0}=1.310^{-5} \mathrm{~s}, \mathrm{a}_{\max }=0.08\right.$ for $\mathrm{H}_{\mathrm{dc}}=1200$ $\mathrm{Oe}$ ) with magnetic slow relaxation observed only below $4 \mathrm{~K}$. This may indicate that the electrostatic environment generated by the $\mathrm{N}_{3} \mathrm{O}_{5}$ coordination sphere in this series of compounds is favorable to oblate ions and not to prolate ones.

In conclusion, spiropyran unit comes out from this work as an original source of phenolate strong donor atom through its isomerization to merocyanine. The association of the phenolate, and of several less charged nitrogen atoms, clearly generates the strongly axial magnetic anisotropy in the reported compound This results in an opening of hysteresis loop, high energy barrier for spin reversal $(216 \mathrm{~K})$ and low distribution of the relaxation times $\left(\alpha_{\max }=0.177\right)$. We have now good hope to obtain architectures outperforming this first case, both in term of magnetic behavior and light-responsivity, through the optimization of the spiropyran binding moiety and replacement of the diketonate ligands.

\section{Acknowledgements}

This work was supported by the Universite de Rennes 1, the CNRS, the Agence Nationale de la Recherche (RuOxLux - ANR12-BS07-0010-01)). G.F.G gratefully acknowledges the European Commission through the ERC-AdG 267746 MolNanoMas (project n. 267746) and the ANR (ANR-13-BS070022-01) for financial support. B.L.G. and G.F.G. thank the French GENCI/IDRIS-CINES center for high-performance computing resources.

Keywords: $\mathrm{SMM} \cdot$ axial anisotropy $\cdot$ merocyanine $\bullet$ hysteresis $•$ ab initio calculation.
[1] a) J. Andreasson, U. Pischel, Chem. Soc. Rev. 2015, 44, 1053-1069; b) S. V. Aradhya, L. Venkataraman, Nat Nano 2013, 8, 399-410; c) D Xiang, X. Wang, C. Jia, T. Lee, X. Guo, Chem. Rev. 2016, 116, 43184440.

[2] M. Irie, T. Fulcaminato, K. Matsuda, S. Kobatake, Chem. Rev. 2014 114, 12174-12277.

[3] F. Meng, Y.-M. Hervault, Q. Shao, B. Hu, L. Norel, S. Rigaut, X. Chen, Nat. Commun. 2014, 5:3023

[4] S. Venkataramani, U. Jana, M. Dommaschk, F. D. Soennichsen, F. Tuczek, R. Herges, Science 2011, 331, 445-448.

[5] a) L. Bogani, W. Wernsdorfer, Nat. Mater. 2008, 7, 179-186; b) D. Gatteschi, R. Sessoli, J. Villain, Molecular Nanomagnets, Oxford University Press, Oxford, 2006; c) C. Benelli, D. Gatteschi,: Introduction to Molecular Magnetism: From Transition Metals to Lanthanides; Wiley, 2015

[6] a) N. Ishikawa, M. Sugita, N. Tanaka, T. Ishikawa, S. Y. Koshihara, Y. Kaizu, Inorg. Chem. 2004, 43, 5498-5500; b) D. E. Freedman, D. M. Jenkins, A. T. lavarone, J. R. Long, J. Am. Chem. Soc. 2008, 130, 2884-2885; c) G. N. Newton, S. Yamashita, K. Hasumi, J. Matsuno, N. Yoshida, M. Nihei, T. Shiga, M. Nakano, H. Nojiri, W. Wernsdorfer, H. Oshio, Angew. Chem., Int. Ed. 2011, 50, 5715-5719; d) L. Norel, M. Feng, K. Bernot, T. Roisnel, T. Guizouarn, K. Costuas, S. Rigaut, Inorg. Chem. 2014, 53, 2361-2363; e) M. Gonidec, E. S. Davies, J. McMaster, D. B. Amabilino, J. Veciana, J. Am. Chem. Soc. 2010, 132, 1756-1760.

[7] a) X. W. Feng, C. Mathoniere, I. R. Jeon, M. Rouzieres, A. Ozarowski, M. L. Aubrey, M. I. Gonzalez, R. Clerac, J. R. Long, J. Am. Chem. Soc. 2013, 135, 15880-15884; b) C. Mathoniere, H. J. Lin, D. Siretanu, R. Clerac, J. M. Smith, J. Am. Chem. Soc. 2013, 135, 19083-19086.

[8] a) M. M. Paquette, B. O. Patrick, N. L. Frank, J. Am. Chem. Soc. 2011 133, 10081-10093; b) M. M. Paquette, R. A. Kopelman, E. Beitler, N. L. Frank, Chem. Commun. 2009, 5424-5426.

[9] a) C. Tu, A. Y. Louie, Chem. Commun. 2007, 1331-1333; b) C. Tu, R. Nagao, A. Y. Louie, Angew. Chem., Int. Ed. 2009, 48, 6547-6551; c) C. Tu, E. A. Osborne, A. Y. Louie, Tetrahedron 2009, 65, 1241-1246.

[10] T. Sakata, D. K. Jackson, S. Mao, G. Marriott, J. Org. Chem. 2008, 73, 227-233.

[11] S. V. Paramonov, V. Lokshin, O. A. Fedorova, J. Photochem. Photobiol., C 2011, 12, 209-236.

[12] T. Sakata, Y. L. Yan, G. Marriott, J. Org. Chem. 2005, 70, 2009-2013.

[13] R. N. Liu, C. M. Zhang, L. C. Li, D. Z. Liao, J. P. Sutter, Dalton Trans. 2012, 41, 12139-12144.

[14] D. Casanova, M. Llunell, P. Alemany, S. Alvarez, Chem. Eur. 2005, 11 1479-1494.

[15] M. Natali, C. Aakeroey, J. Desper, S. Giordani, Dalton Trans. 2010, 39, 8269-8277.

[16] M. Natali, S. Giordani, Chem. Soc. Rev. 2012, 41, 4010-4029.

[17] J. L. Bahr, G. Kodis, L. de la Garza, S. Lin, A. L. Moore, T. A. Moore, D. Gust, J. Am. Chem. Soc. 2001, 123, 7124-7133.

[18] a) M. Kubinyi, O. Varga, P. Baranyai, M. Kallay, R. Mizsei, G. Tarkanyi, T. Vidoczy, J. Mol. Struct. 2011, 1000, 77-84; b) M. Natali, L. Soldi, S. Giordani, Tetrahedron 2010, 66, 7612-7617.

[19] J. D. Winkler, C. M. Bowen, V. Michelet, J. Am. Chem. Soc. 1998, 120, 3237-3242.

[20] D. N. Woodruff, R. E. P. Winpenny, R. A. Layfield, Chem. Rev. 2013, 113, 5110-5148.

[21] a) T. T. da Cunha, J. Jung, M. E. Boulon, G. Campo, F. Pointillart, C. L. M. Pereira, B. Le Guennic, O. Cador, K. Bernot, F. Pineider, S. Golhen, L. Ouahab, J. Am. Chem. Soc. 2013, 135, 16332-16335; b) J. Jung, X. Yi, G. Huang, G. Calvez, C. Daiguebonne, O. Guillou, O. Cador, A. Caneschi, T. Roisnel, B. Le Guennic, K. Bernot, Dalton Trans. 2015, 44, 18270-18275; c) J. D. Rinehart, J. R. Long, Chem. Sci. 2011, 2, 20782085.

[22] J. Liu,Y.-C. Chen, J.-Li. Liu, V. Vieru, L. Ungur J.-H. Jia L. F. Chibotaru, Y. Lan, W. Wernsdorfer, S. Gao, X.-M. Chen, M.-L. Tong, J. Am. Chem. Soc. 2016, 138, 5441-5450. 
[23] F. Pointillart, K. Bernot, S. Golhen, B. Le Guennic, T. Guizouarn, L. Ouahab, O. Cador, Angew. Chem., Int. Ed. 2015, 54, 1504-1507. 


\section{COMMUNICATION}

$4 f$ ion-induced isomerization of a spiropyran ligand produces a mononuclear merocyanine dysprosium complex with SMM behaviour.

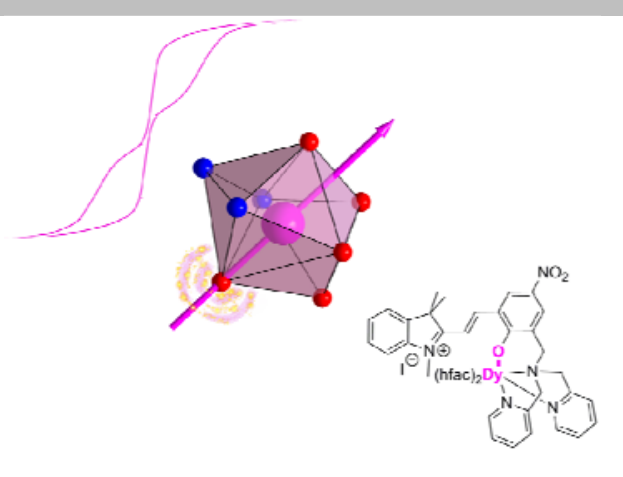

Pramila Selvanathan, Gang Huang, Thierry Guizouarn, Thierry Roisnel, Guglielmo Fernandez-Garci, Federico Totti, Boris Le Guennic, Guillaume Calvez, Kévin Bernot, * Lucie Nore/* and Stéphane Rigaut

Highly axial magnetic anisotropy in a N3O5 dysprosium(III) coordination environment generated by a merocyanine ligand 